\title{
Five-Year Trend in Hydrogenated Vegetable Oil Consumption among Northern Iranian Families
}

\author{
Gholamreza Veghari, MPhil, Mehdi Sedaghat, MD, Siavash Maghsodlo, MD, PhD, \\ Samieh Banihashem, MD, Pooneh Moharloei, MD, Abdolhamid Angizeh, BS, \\ Ebrabim Tazik, BS, and Abbas Moghaddami, MS
}

Background: The main aim of this study was to assess the trends in hydrogenated vegetable oil (HVO) consumption and some related factors among northern Iranian families from 2006 to 2010.

Methods: A cross-sectional, population-based study was conducted with 6497 subjects, 15 to 65 years old, who were chosen by multistage cluster random sampling. The subjects were randomly chosen by 325 clusters with an equal size $(n=20$ subjects $)$. A multidimensional questionnaire including sociodemographic questions and type of cooking oil used were administered by interviewers.

Results: The percentages of the sample reporting HVO consumption across the 5 years are as follows: 2006, 85.2\%; 2007, 79.7\%; 2008, 75.9\%; 2009, 59.3\%; and 2010, 55.7\%. Consumption decreased 29.5\% during the 5 years of study and an average of $5.9 \%$ per year $(P<.05)$. The estimated odds ratio of HVO consumption in rural areas verus urban areas was 2.59 (95\% confidence interval [CI], 2.31-2.90); for poor compared with good economic level the odds ratio was 3.99 (95\% CI, 3.13-5.10 for; for the uneducated versus college-educated sample it was 5.75 (95\% CI, 4.10-8.17); and the odds ratio was $3.34(95 \% \mathrm{CI}$, 2.51-4.45) for Sisstani compared with Fars-native ethnic group.

Conclusion: HVO consumption decreased during the 5-year study (2006 to 2010), but HVO is still used extensively in northern Iran. Preventive early intervention strategies are needed to target uneducated and poor families, with an emphasis on the Sisstanish ethnic group, to increase awareness about the negative consequences of HVO consumption. (J Am Board Fam Med 2013;26:778-783.)

Keywords: Epidemiology, Ethnicity, Iran, Nutrition Surveys, Vegetable Oils

Prevention of cardiovascular disease (CVD) is a health priority world wide. ${ }^{1}$ Genetics, physical activity, and food intake are well-known risk factors in the development of CVD. ${ }^{2}$ It is notable that higher intake of trans fatty acids has been documented to increase the risk of $\mathrm{CVD},{ }^{3}$ type 2 diabetes, ${ }^{4}$ and metabolic syndrome. ${ }^{5}$ Hydrogenated vegetable oil (HVO), a rich source of saturated fatty acids (average, $14 \mathrm{~g} / 1000 \mathrm{kcal}$ ) and trans fatty acids (23\% to $36 \%$ ), are used extensively by Iranian fam-

This article was externally peer reviewed.

Submitted 25 November 2012; revised 5 February 2013; accepted 26 April 2013.

From the Department of Biochemistry and Nutrition, School of Medicine, Golestan University of Medical Sciences, Gorgan, Iran; Deputy of Health, Golestan University of Medical Sciences, Gorgan, Iran.

Funding: none.

Conflict of interest: none declared.

Corresponding author: Gholamreza Veghari, MPhil, Ischemic Disorders Research Center, Golestan University of Medical Sciences, Gorgan, Iran (E-mail: grveghari@yahoo.com). ilies ${ }^{6}$ - twice the amount used than in some developed countries. ${ }^{7}$ Previous investigators have reported a decreased use of saturated fatty acids and an intention to raise the intake of polyunsaturated fatty acids in developed countries. ${ }^{8,9}$ The ability to modify eating behavior, however, is not the same in all societies ${ }^{10}$; it may be related to food production $^{11}$ and lifestyle. ${ }^{12}$ Currently, 1.6 million people reside in the Golestan province of northern Iran, southeast of the Caspian sea. In this region, approximately $66 \%$ of the population is 15 to 65 years old, with $44 \%$ and $56 \%$ living in urban and rural areas, respectively. ${ }^{13}$ Many ethnic groups live in this area, including Fars-native, Turkman, and Sisstani; agriculture is the primary source of employment in villages. With the high use of HVOs by Iranian families, information is needed to design early intervention and prevention strategies to decrease the risk for CVD. The purpose of this study was to assess the trend in HVO consumption along with 
sociodemographic factors among northern Iranian families over a 5-year period (2006 to 2010).

\section{Methods}

A cross-sectional, population-based study was conducted with 6497 individuals, 15 to 65 years old, who were chosen by a multistage cluster random sampling in 5 separate stages in 11 towns in Golestan province. With an almost $50 \%$ prevalence rate, a confidence level of $95 \%$, and a maximum marginal error of about 0.04 , an estimated sample size was calculated as at least 600 subjects in each year. For more efficiency the sample size was increased 1000 subjects. In the first stage (2006) the study recruited 2500 participants in a Comprehensive Non-Communicable Disease Survey. One stage was established each year: 2500 participants in 2006, 1000 participants in 2007, 999 participants in 2008, 998 participants in 2009, and 1000 participants in 2010 in urban and rural areas. Among 11 towns in the area studied, 325 clusters were randomly selected with equal size of 20 subjects. In the beginning, the clusters were chosen randomly using a systematic sampling technique by postal code in urban areas and using family codes from primary health centers in rural areas. In the second stage, in each cluster we selected 10 men and 10 women, rotating from the right to the left of the cluster. The distribution of clusters in each town depended on their population size. All family members 15 to 65 years old living in a household were included in our study.

Trained staff administered the multidimensional questionnaire that contained demographic characteristics including residential area, sex, age, ethnicity, educational level, economic status, and type of cooking oil used in the home. Ethnicity, educational levels, and economic status were estimated in only 3 stages. The edible oils used for daily cooking were defined as oil consumption and they were classified in 3 groups: (1) HVO, (2) non-HVO, and (3) other edible oils, including animal oils, butter, and margarine.

The ethnicity variable included 3 types: (1) Farsnative (recognized with the same name in society and they are the natural inhabitants of the area); (2) Turkman (called a pure race because intermarriage between them and other ethnic groups were rare); and (3) Sisstani (residents in the area study who immigrated from Sisstan and Baluchestan prov- inces in eastern Iran about half a century ago). Economic status with regard to the Iranian socioeconomic situation, was categorized based on 6 facilities items: a separate freezer, separate kitchen, vacuum cleaner, computer, separate bathroom, and washing machine, with an equal score given for each of them. The economic status variable was scored as follows: poor, $\leq 2$; intermediate, 3 or 4 ; and good, $\geq 5$. Educational level was classified as 4 groups: uneducated (unable to read or write), 1 to 6 years of schooling, 7 to 12 years of schooling, and college.

After collecting data over 5 years and merging them into one file, SPSS software version 16.0 (IBM, Chicago, IL) was used for statistical analysis. Cochran's test, a $\chi^{2}$ test, and logistic regression were used to compare the groups, and statistical significance was defined as $P<.05$. This study was approved by an ethical research committee and consent was received from all subjects.

\section{Results}

Slightly more than half $(55.1 \%)$ of the sample were Fars-native; $30.8 \%$ were Turkman, and $14.1 \%$ were Sisstanish ethnic groups. The sample was evenly distributed by sex and area of residence. The

\section{Table 1. Sociodemographic Factors of Subjects at Baseline}

\begin{tabular}{lc}
\hline Characteristics & Subjects \\
\hline Residential area $(\mathrm{n}=6497)$ & \\
$\quad$ Urban & $2707(41.7)$ \\
Rural & $3790(58.3)$ \\
Sex $(\mathrm{n}=6497)$ & \\
$\quad$ Male & $3255(50.1)$ \\
Female & $3245(49.9)$ \\
Ethnicity $(\mathrm{n}=3500)$ & \\
Fars (native) & $1929(55.1)$ \\
Turkman & $1078(30.8)$ \\
Sisstani & $494(14.1)$ \\
Economic status $(\mathrm{n}=3500)$ & \\
Poor & $808(23.1)$ \\
Moderate & $1782(50.9)$ \\
Good & $910(26.0)$ \\
Educational level $(\mathrm{n}=3500)$ & \\
Uneducated & $1033(29.5)$ \\
$1-6$ years of schooling & $1446(41.3)$ \\
$7-12$ years of schooling & $794(22.7)$ \\
College & $227(6.5)$ \\
\hline
\end{tabular}

Data are $\mathrm{n}(\%)$. 
Table 2. Trends in the of Type of Cooking Oil Used Among Families in Northern of Iran During 2006 to 2010

\begin{tabular}{|c|c|c|c|c|c|c|}
\hline \multirow[b]{2}{*}{ Residential Area } & \multicolumn{5}{|c|}{ Years } & \multirow[b]{2}{*}{ Total } \\
\hline & 2006 & 2007 & 2008 & 2009 & 2010 & \\
\hline \multicolumn{7}{|l|}{ Urban } \\
\hline \multicolumn{7}{|l|}{ Cooking oil } \\
\hline HVO & $877(75.3)$ & $324(70.4)$ & $231(64.2)$ & $155(41.0)$ & $140(40.6)$ & $1727(63.8)$ \\
\hline Non-HVO & $280(24.1)$ & $130(28.3)$ & $113(31.4)$ & $216(57.1)$ & $188(54.5)$ & $927(34.2)$ \\
\hline Others & 7 (0.6) & $6(1.3)$ & $16(4.4)$ & $7(1.9)$ & $17(4.9)$ & $53(2.0)$ \\
\hline Total & $1164(100)$ & $460(100)$ & $360(100)$ & $378(100)$ & $345(100)$ & $2707(100)$ \\
\hline \multicolumn{7}{|l|}{ Rural } \\
\hline \multicolumn{7}{|l|}{ Cooking oil } \\
\hline $\mathrm{HVO}$ & $1254(93.9)$ & 473 (87.6) & $527(82.5)$ & $437(70.5)$ & $417(63.7)$ & $3108(82.0)$ \\
\hline Non-HVO & $75(5.6)$ & $64(11.9)$ & $102(16.0)$ & $180(29.0)$ & $216(33.0)$ & $637(16.8)$ \\
\hline Others & $7(0.5)$ & $3(0.6)$ & $10(1.6)$ & $3(0.5)$ & $22(3.4)$ & $45(1.2)$ \\
\hline Total & $1336(100)$ & $540(100)$ & $639(100)$ & $620(100)$ & $655(100)$ & $3790(100)$ \\
\hline \multicolumn{7}{|l|}{ Total } \\
\hline \multicolumn{7}{|l|}{ Cooking oil } \\
\hline $\mathrm{HVO}$ & $2131(85.2)$ & $797(79.7)$ & $758(75.9)$ & $592(59.3)$ & $557(55.7)$ & $4835(74.4)$ \\
\hline Non-HVO & $355(14.2)$ & $194(19.4)$ & $215(21.5)$ & $396(39.7)$ & $404(40.4)$ & $1564(24.1)$ \\
\hline Others & $14(0.6)$ & $9(0.9)$ & $26(2.6)$ & $10(1.0)$ & $39(3.9)$ & $98(1.5)$ \\
\hline Total & $2500(100)$ & $1000(100)$ & $999(100)$ & $998(100)$ & $1000(100)$ & $6497(100)$ \\
\hline
\end{tabular}

Values are $\mathrm{n}(\%)$.

HVO, hydrogenated vegetable oil.

mean age was $39.2 \pm 14.6$ years. The uneducated category described $29.5 \%$ of subjects and was more common in women (Table 1).
HVOs were consumed by $85.2 \%$ in $2006,79.7 \%$ in $2007,75.9 \%$ in $2008,59.35$ in 2009 , and $55.7 \%$ in 2010. In general, HVO consumption decreased

Table 3. Comparison of the Kind of Cooking Oil Used Among Families in Northern Iran, by Sociodemographic

\section{Factors}

\begin{tabular}{|c|c|c|c|c|c|}
\hline \multirow[b]{2}{*}{ Characteristics } & \multirow[b]{2}{*}{$\mathrm{N}$} & \multicolumn{3}{|c|}{ Type of Cooking Oil } & \multirow[b]{2}{*}{$P$ Value } \\
\hline & & HVO & Non-HVO & Others & \\
\hline \multicolumn{6}{|l|}{ Sex } \\
\hline Male & 3252 & $2429(74.7)$ & $771(23.7)$ & $52(1.6)$ & .487 \\
\hline Female & 3245 & $2406(74.1)$ & $793(24.5)$ & $46(1.4)$ & \\
\hline \multicolumn{6}{|l|}{ Ethnicity } \\
\hline Fars (native) & 1929 & $1167(60.5)$ & 708 (36.7) & $54(2.8)$ & .001 \\
\hline Turkman & 1078 & $697(64.7)$ & $371(34.4)$ & $10(0.9)$ & \\
\hline Sisstani & 494 & $369(74.7)$ & $121(24.5)$ & $4(0.8)$ & \\
\hline \multicolumn{6}{|l|}{ Economic status } \\
\hline Poor & 808 & $700(86.7)$ & $99(12.2)$ & $9(1.1)$ & .001 \\
\hline Moderate & 1782 & $1422(79.8)$ & $330(18.5)$ & $29(1.6)$ & \\
\hline Good & 910 & $564(62.0)$ & $333(36.6)$ & $13(1.4)$ & \\
\hline \multicolumn{6}{|l|}{ Educational level } \\
\hline Uneducated & 1033 & 941 (91.1) & $85(8.2)$ & $7(0.7)$ & .001 \\
\hline $1-6$ years of schooling & 1446 & $1239(85.7)$ & $199(13.8)$ & $8(0.6)$ & \\
\hline $7-12$ years of schooling & 794 & $603(75.9)$ & $184(23.2)$ & $7(0.9)$ & \\
\hline College & 227 & $145(63.9)$ & $81(35.7)$ & $1(0.4)$ & \\
\hline
\end{tabular}

Values are n (\%) unless otherwise indicated.

HVO, hydrogenated vegetable oil. 
$29.5 \%$ during the 5 -year period, with a mean decrease of $5.9 \%$ each year $(P<.05)$. On average, the HVO consumption in urban areas $(63.8 \%)$ was significantly lower than in rural areas $(82.0 \%)(P<$ $.001)$. Overall, over the 5 -year period, people in urban and rural areas tended to decrease HVO consumption (Table 2).

When comparing the 3 ethnic groups, the Farsnative families $(60.5 \%)$ had the lowest and Sisstani families $(74.7 \%)$ had the highest consumption of HVOs $(P<.001)$. HVO consumption was inversely associated with educational level $(P=.001)$. The majority of uneducated subjects (91.1\%) tended to consume HVO, whereas only $63.9 \%$ of college-educated subjects consumed did so. There was a significant disparity in HVO consumption in 3 economic conditions $(P=.001)$. Compared with good economic level (62.0\%), low-income families preferred to use HVOs as their edible oil (86.7\%). Overall, more than half of families in the north of Iran were consuming HVOs (Table 3).

Multiple logistic regression was used to identify variables that contributed to HVO consumption. Estimated odds ratios were 2.59 (95\% confidence interval $[\mathrm{CI}], 2.31-2.90)$ in rural areas compared with urban areas; 3.99 (95\% CI, 3.13-5.10) for poor economic level compared with good economic level; 5.75 (95\% CI, 4.10-8.17) for uneducated people compared with college-educated people; and 3.34 (95\% CI, 2.51-4.45) for Sisstanish ethnic group compared with Fars-native ethnic group; sex was not significantly related to HVO consumption (Table 4). The use of 3 types of edible oil during the 5 -year study period was not completely the same. Despite the downward trend of HVO consumption, there was an upward trend in the use of non-HVOs (Figure 1).

\section{Discussion}

This study estimated the trend in HVO consumption over 5 years (2006 to 2010) in families in northern Iran. Compared with 2006, the consumption of HVO decreased $29.5 \%$ in 2010 , whereas at least half of families in northern Iran used HVO as an edible oil. Studies about edible oils are scarce in Iran. In Semnan (a province in central Iran), HVO consumption decreased from $56.4 \%$ to $36.8 \%$ following an intervention and education program. ${ }^{14}$ The report of Comprehensive Studies of Household Food Stuff Consumption Patterns estimated
Table 4. Results of Multiple Logistic Regression Analysis Between hydrogenated vegetable oil (HVO) Consumption and the Related Risk Factors Among Families in Northern Iran

\begin{tabular}{|c|c|c|}
\hline Risk Factor & OR $(95 \% \mathrm{CI})$ & $P$ Value \\
\hline \multicolumn{3}{|l|}{ Sex } \\
\hline Men* & 1 & .613 \\
\hline Women & $1.03(0.92-1.15)$ & \\
\hline \multicolumn{3}{|l|}{ Residential area } \\
\hline Urban* & 1 & .001 \\
\hline Rural & $2.59(2.31-2.90)$ & \\
\hline \multicolumn{3}{|l|}{ Ethnicity } \\
\hline Fars (native)* & 1 & .001 \\
\hline Turkman & $1.20(1.01-1.41)$ & \\
\hline Sisstani & $3.34(2.51-4.45)$ & \\
\hline \multicolumn{3}{|l|}{ Economic status } \\
\hline Good* & 1 & .001 \\
\hline Poor & $3.99(3.13-5.10)$ & \\
\hline Moderate & $2.43(3.03-2.90)$ & \\
\hline \multicolumn{3}{|l|}{ Educational level } \\
\hline College* & 1 & .001 \\
\hline Uneducated & $5.75(4.10-8.17)$ & \\
\hline $1-6$ years of schooling & $3.39(2.49-4.61)$ & \\
\hline $7-12$ years of schooling & $1.79(1.30-2.45)$ & \\
\hline
\end{tabular}

${ }^{*}$ Reference category.

$\mathrm{CI}$, confidence interval; OR, odds ratio.

that consumption of HVO and non-HVOs by Iranian families are $50.4 \%$ and $3.5 \%$, respectively. ${ }^{15}$ The trend of saturated fatty acids in daily food is declining in some areas in worldwide. ${ }^{8,16-20}$ In the United States, a downward trend in the consumption of trans fatty acids was seen, decreasing from $3 \%$ (1980 to 1982$)$ to $2.2 \%(1995 \text { to } 1997)^{21}$; in the Netherlands, the average of total daily energy intake declined from $4.3 \%$ to $1.9 \%$ over 10 years. $^{22}$ This study suggests that although HVO consumption decreased significantly in northern Iran, it remains a health problem.

We observed that uneducated, low income, and living in rural areas are associated with high intake of HVO. An educational intervention modified food behaviors ${ }^{14}$ more successfully among Iranian women with higher education. ${ }^{23}$ Others have reported an association between sociodemographic factors and food behaviors. ${ }^{24,25}$ The strong relationship between educational level ${ }^{26}$ and CVD control rates ${ }^{27,28}$ also has been previously reported. In agreement with these studies, promotion of socioeconomic status and educational level positively changed food behavior, with declining HVO con- 
Figure 1. Comparison of cooking oils used among families in northern Iran, from 2006 to 2010. HVO, hydrogenated vegetable oil.

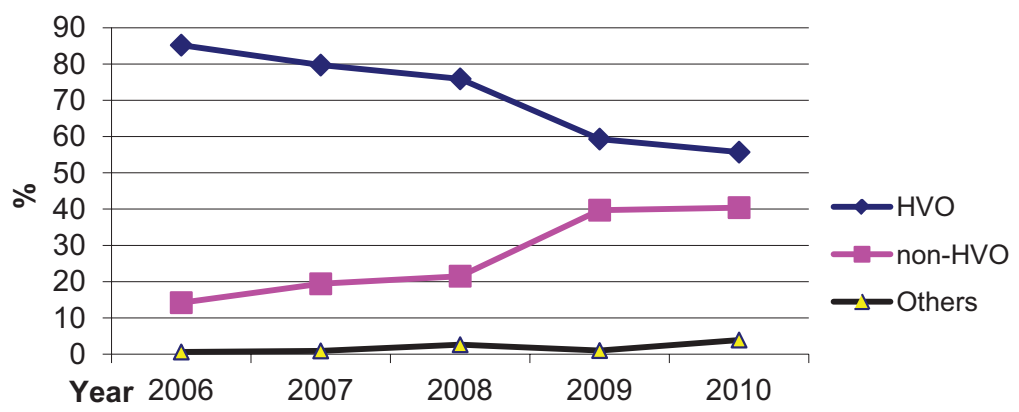

sumption among families in northern Iran. HVO is less expensive than other edible oils in Iran, which likely accounts for its greater consumption among low-income families.

We found differences in HVO consumption among 3 ethnic groups, and it was greater in Sisstanish families than other ethnic groups. Previous studies in northern $\operatorname{Iran}^{29,30}$ reported low socioeconomic criteria and poor nutrition in the Sisstanish ethnic group. Others have shown differences in edible oil consumption among other ethnic groups. ${ }^{9,31,32}$

Human nutrition is multifaceted, culturally based, and influenced by education, income, geographical environment, religion, and habits. Iran is a developing country in a transitional nutrition phase. ${ }^{33}$ In Iran, edible oil production has been directly promoted by the government as a priority goal, and it is necessary to establish a national strategic plan to reduce $\mathrm{HVO}$ production.

Our study demonstrated a downward trend in HVO consumption over a 5 -year period. Educational level and economic status are associated with high HVO consumption. Educational level, socioeconomic condition, and health awareness are all increasing in Iran; therefore, we expect to see a further reduction in $\mathrm{HVO}$ consumption in the future.

A limitation of the study is that we did not evaluate the influence of many sociodemographic factors on HVO consumption, including religion, equal access to types of oil, and intake of other fat content. Other limitations include not having an intervention to change the cooking oil during the 5 years studied and not having an exact classification for economic status.

\section{Conclusion}

Although HVO consumption declined during the past years, its use is common in half of families in northern Iran. Illiteracy and poverty are risk factors for high HVO consumption. There is a need for health education about the role of saturated fatty acids in CVD, targeting less educated and poor families in particular, especially those in the Sisstanish ethnic group.

The authors thank the medical and administrative staff of the Primary Health Care Centers for their valuable assistance during the field work. This study, based on 416,183 official documents, was justified for publication and created from a provincial incommunicable data study and was supported by the Health Office of Golestan University of Medical Sciences.

\section{References}

1. Kones R. Primary prevention of coronary heart disease: integration of newdata, evolving views, revised goals, and role of rosuvastatin in management. A comprehensive survey. Drug Des Devel Ther 2011; 5:325-80.

2. Bolen JC, Rhodes L, Powell-Griner EE, Bland SD, Holtzman D. State-specific prevalence of selected health behaviors by race and ethnicity-Behavioral Risk Factor Surveillance System, 1997. MMWR CDC Surveill Summ 2000;49:1-60.

3. Oomen CM, Ocke MC, Feskens EJ, van Erp-Baart MA, Kok FJ, Kromhout D. Association between trans fatty acid intake and 10-year risk of coronary heart disease in the Zutphen Elderly Study: a prospective population-based study. Lancet 2001;357: $746-51$.

4. Pisabarro RE, Sanguinetti C, Stoll M, Prendez D. High incidence of type 2 diabetes in peroxisome proliferator-activated receptor gamma2 Pro12Ala carriers exposed to a high chronic intake of trans fatty acids and saturated fatty acids. Diabetes Care 2004;27:2251-2.

5. Freire RD, Cardoso MA, Gimeno SG, Ferreira SR; Japanese-Brazilian Diabetes Study Group. Dietary fat is associated with metabolic syndrome in Japanese Brazilians. Diabetes Care 2005;28:1779-85. 
6. Mozaffarian D, Abdollahi M, Campos H, Houshiar$\operatorname{rad} \mathrm{A}$, Willett WC. Consumption of trans fats and estimated effects on coronary heart disease in Iran. Eur J Clin Nutr 2007;61:1004-10.

7. Mozaffarian D, Katan MB, Ascherio A, Stampfer MJ, Willett WC. Transfatty acids and cardiovascular disease. N Engl J Med 2006;354:1601-13.

8. Craig-Schmidt MC. World-wide consumption of trans fatty acids. Atheroscler Suppl 2006;7:1-4.

9. Popkin B, Siega-riz A, Haines P, Jahns L. Where's the fat? Trends in U.S. diets 1965-1996. Prev Med 2001;2:245-54.

10. Morabia A, Bernstein MS, Heritier S, Beer-Borst S. A Swiss population-based assessment of dietary habits before and after the March 1996 'mad cow disease’ crisis. Eur J Clin Nutr 1999;53:158-63.

11. Harnack LJ, Jeffery RW, Boutelle KN. Temporal trends in energy intake in the United States: an ecologic perspective. Am J Clin Nutr 2000;71:1478-84.

12. Mulder M, Ranchor AV, Sanderman R, Bouma J, van den Heuvel WJ. The stability of lifestyle behavior. Int J Epidemiol 1998;27:199-207.

13. Statistical Center of Iran. 2011 National Census of Population and Housing. The Technical Report. http://www.amar.org.ir/Default.aspx?tabid=765. Accessed June 10, 2012.

14. Karimi B, Ghorbani R, Haghighi S, et al. Effects of educational intervention on women's behaviors in utilization of oils and fats [article in Persian]. Koomesh 2010;11:255-62.

15. The comprehensive studies of household food stuff consumption pattern and nutritional status in country. National report, 1379-81 [article in Persian]. Tehran: Institute of Nutrition Sciences; 2005.

16. van Poppel G. Intake of transfatty acids in western Europe: the TRANSFAIR study. Lancet 1998;351: 1099.

17. Oomen CM, Ocké MC, Feskens EJ, van Erp-Baart MA, Kok FJ, Kromhout D. Association between trans fatty acid intake and 10-year risk of coronary heart disease in the Zutphen Elderly Study: a prospective population-based study. Lancet 2001;357: $746-51$.

18. Lee S, Harnack L, Jacobs DR Jr, Steffen LM, Luepker RV, Arnett DK. Trends in diet quality for coronary heart disease prevention between 19801982 and 2000-2002: the Minnesota Heart Survey. J Am Diet Assoc 2007;107:213-22.

19. Stephen AM, Wald NJ. Trends in individual consumption of dietary fat in the United States, 19201984. Am J Clin Nutr 1990;52:457-69.
20. Centers for Disease Control and Prevention (CDC). Trends in intake of energy and macronutrientsUnited States, 1971-2000. MMWR Morb Mortal Wkly Rep 2004;53:80-2.

21. Harnack L, Lee S, Schakel SF, Duval S, Luepker $\mathrm{RV}$, Arnett DK. Trends in the trans-fatty acid composition of the diet in a metropolitan area: the Minnesota Heart Survey. J Am Diet Assoc 2003;103: 1160-6.

22. Hulshof KF, Brussaard JH, Kruizinga AG, Telman J, Lowik MR. Socio-economic status, dietary intake and $10 \mathrm{y}$ trends: the Dutch National Food Consumption Survey. Eur J Clin Nutr 2003;57:128-37.

23. Sonestedt E, Wirfält E, Gullberg B, Berglund G. Past food habit change is related to obesity, lifestyle and socio-economic factors in the Malmo Diet and Cancer Cohort. Public Health Nutr 2005;8:876-85.

24. Parmenter K, Waller J, Wardle J. Demographic variation in nutrition knowledge in England. Health Educ Res 2000;15:163-74.

25. Lopez-Azpiazu I, Martinez-Gonzalez MA, LeonMateos A, Kearney J, Gibney M, Martinez JA. Stages of dietary change and nutrition attitudes in the Spanish population. Public Health 2000;114:183-9.

26. Gazmararian JA, Baker DW, Honig EG, Lee TM, Nowlan A. Health literacy and knowledge of chronic disease. Patient Educ Couns 2003;51:267-75.

27. Erceg M, Ivicević-Uhernik A, Kern J, Vuletić S. Is there any association between blood pressure and education level? The CroHort study. Coll Antropol 2012;36(Suppl 1):125-9.

28. Lyra R, Silva Rdos S, Montenegro Junior RM, Matos MV, Cézar NJ, Fernandes VO, Maurícioda-Silva L. High prevalence of arterial hypertension in a Brazilian Northeast population of low education and income level, and its association with obesity and metabolic syndrome. Rev Assoc Med Bras 2012;58: 209-14.

29. Veghari G, MansourianAR. Obesity among mothers in rural Golestan-Iran (south-east of Caspian sea). Iran J Public Health 2007;36:71-6.

30. Veghari G, Asadi J, Eshghinia S. Impact of ethnicity upon body composition assessment in Iranian northern children. J Clin Diagn Res 2009;3:1779-83.

31. Lin CT, Yen ST. Knowledge of dietary fats among US consumers. J Am Diet Assoc 2010;110:613-8.

32. Block JP, Scribner RA, DeSalvo KB. Fast food, race/ ethnicity, and income: a geographic analysis. Am J Prev Med 2004;27:211-7.

33. Ghassemi H, Harrison G, Mohammad K. An accelerated nutrition transition in Iran. Public Health Nutr 2002;5(1A):149-55. 